\title{
Filling the parenting gap? grandparent involvement with U.K. adolescents
}

\begin{abstract}
With people living longer and more mothers working, there is some evidence that grandparents are more involved in rearing the next generation. Although there is research in the United Kingdom on kinship care, there is no national research on the extent of grandparent involvement from the perspective of young people. This, the first national survey of 1,478 adolescents in England and Wales, demonstrates the very considerable amount of informal care given by grandparents to adolescents. The findings showed that factors in the wider ecology of children, their parents, grandparents, and the community influenced grandparentठ grandchild involvement. In particular, more regular contact and stronger grandparent/grandchild closeness, greater parental encouragement to visit grandparents, better health in grandparents, and less deprivation in the community were significantly associated with more active grandparent involvement. The article concludes that because grandparents may be filling the parenting gap for hard-working parents, there is a case for greater recognition of their role as family supporters.
\end{abstract}

Keyword: Grandparents; Grandparent involvement; Intergenerational relations; Closeness 